"Across northern Idaho, Montana, and the Dakotas service virtually was suspended. Like unsatisfactory conditions prevailed on all the northern transcontinental lines.

"For several hours during the early morning cable communication vid the Newfoundland cables of the Western Union was all but paralysed."

During the progress of the aurora, Mr. Frank Sullivan and Mr. E. P. Hubble, of this observatory, tried the wirless receiver here, with which time-signals are received from Arlington, Virginia, Mr. Sullivan at $\mathrm{I} 4 \mathrm{~h} .45 \mathrm{~m}$., when the arch was strong but not active, and $\mathrm{Mr}$. Hubble at 2oh. om., when the greatest display occurred. They found in both cases that the static conditions were normal. Mr. Sullivan reports that it was unusually quiet.

Yerizes Observatory, Williams Bay, Wisconsin, June 25.

\section{The Magnetic Storm and Solar Disturbance of June 17, 1915.}

A CORRECTION is necessary for the value of $\mathrm{I}^{\prime}$ of arc displacement for the H.F., given in my letter published in Nature of June 24. It should read, line 18 $\left(I^{\prime}=4.0 \times 10^{-5}\right.$ C.G.S. units). There is also an ambiguity in the preceding line, in the use of the word displacement. The extreme values of the greatest oscillation in the H.F. about $4 . \mathrm{r}_{5}$ p.m. amounted to $100^{\prime}$, as stated, but the maximum displacement was $76^{\prime}$, the value of the base line being $24^{\prime}$.

In his very interesting letter on this subject (NATURE, July r), Dr. Chree mentions several dates on which sudden movements of the magnets occurred, which are presumably of cosmic origin. It may also be of interest to compare the state of the solar surface on these dates with these sudden movements. The first occurred at I p.m. on June I6. On this date the two sympathetic groups of spots, which I have associated with the magnetic storm of June I7, evinced considerable disturbance, the faculæ in the neighbourhood of these two groups, as also bright faculæ conjoined with two other groups nearer the E. limb, showing a decided drift towards the sointh. On June I8, as already described in niy last letter, the whole of the region between these two groups was violently disturbed, and the faculæ, which must have been very bright to be visible in the middle regions of the sun, showed the same southerly drift. As this was visually the most disturbed region of the sun, and, moreover, it was near the heliographic position of the earth, it seemed most likely that this region was the one connected with the magnetic storm, if any such direct connection exists.

On June I4 a bright compact patch of faculæ appeared in the N.E. quadrant on the sun's limb, in which were a few small dots. This new disturbance continued to grow, until on June 21 it had developed into a fine group of large spots near the central meridian. Its mean approximate position was $+17^{\circ}$ latitude, and $35^{\circ}$ longitude. This region was also much disturbed on June I9. Dr. Chree directs attention to the considerable magnetic disturbance which commenced at 3.I0 p.m. on June $2 \mathrm{I}$ with a sudden movement of the H.F. magnet. Dr. Chree also mentinns another sudden commencement on June 7 "of considerable size at a time when Father Cortie tells us the sun was "almost free from spots." On that date there was only one group of very small spots at mean latitude $+2 \mathrm{I}^{\circ}$ and longitude $198^{\circ}$, in a ring of faculæ. But $I$ find on consulting our solar drawings that NO. 2385 , VOL. 95$]$
M. Henroteau, the observer, has made the following note on the drawing of June 8 , with regard to this group of very small spots: "The region of the spots seems very disturbed."

Finally, that quiet magnetic conditions show the twenty-seven day period is not inconsistent with, but would naturally follow from, successive synodic presentment earthwards of an undisturbed hemisphere of the sun.

Stonyhurst College Observatory, July 4.

\section{Use of Tyrosine in Promoting Organic Growth.}

I DESIRE to direct the attention of readers of NATURE to the influence of tyrosine in promoting the growth and multiplication of any organisms that may be found in tubes five to ten months after they have been hermetically sealed and sterilised, as described in "The Origin of Life," second edition, I9I3, and NATURE of January 22, I9I4.

The June number of the Proceedings of the Royal Society of Medicine contains an illustrated communication dealing with the effects of this powerful auxetic when used in the form of a 0.05 per cent. solution. Its influence was tested on a large number of tubes ripe for examination, containing five different kinds of experimental solutions (the constitution of which is given) by adding, with all necessary precautions, about twenty drops of the tyrosine solution to each tube when it was opened. The tubes were then reclosed and replaced in the incubator for three to four weeks. When the contents of these tubes were reexamined after such an interval a very considerable growth and multiplication of unmistakable organisms were found to have taken place, thus tending to disprove the two principal doubts that had been urged against the original experiments by showing (I) that what were found were not mere pseudo-organisms; or (2) organisms which had pre-existed in the solutions, and had been killed by the sterilising process. Photomicrographs of the organisms taken from the tubes before, as well as after, the addition of the tyrosine show its great influence in favouring the multiplication of bacteria, torulæ, and moulds.

I have quite lately heard from the brothers Mary (Institut de Biophysique, Paris) that they have been similarly successful in obtaining from some of their tubes, after the addition of tyrosine, plenty of budding torulæe, as well as delicate spore-bearing moulds, and that they are about to publish an account of their investigation.

The last number of the Proceedings of the Royal Society (B. 609) contains an interesting paper by Prof. Benjamin Moore and W. G. Evans, in which they describe and figure some simple pseudo-organisms, of a kind with which I am quite familiar, obtained from a limited number of tubes containing solutions apparently similar to some of those which I have used. I have prepared and examined more than a thousand of these tubes, and among them have found many barren series. A comparison of their illustrations with mine will show that they have hitherto met with totally different objects. It is true, however, that some of their finds, under the low magnification which they employ, have a superficial resemblance to matted or twisted hyphæ of moulds (see especially Figs. I, 7, and $\mathrm{II}$ ).

The simplest solution from which I have obtained different kinds of moulds, and which I can recommend to others, is one made from ro per cent. solutions of iron sulphate and potassium ferrocyanide, in which one drop of the former and two of the latter are added to each 30 c.c. of distilled water. The iron stock 